\title{
Same polarity polaron and bipolaron scattering on conducting polymers
}

\author{
Maurício Bellissimo Falleiros ${ }^{1 *}(\mathrm{PG})$, Geraldo Magela e Silva $^{2}(\mathrm{PQ})$ \\ mauricio.falleiros@ueg.br \\ ${ }^{1}$ Goias State University , 75132-400, Anapolis/GO - Brazil, \\ currently at Institute of Physics - University of Brasilia, 70.919-970, Brasília/DF - Brazil \\ ${ }^{2}$ Institute of Physics - University of Brasília, 70.919-970, Brasília/DF - Brazil
}

Keywords: polaron, bipolaron, scattering, conducting polymer

\begin{abstract}
Conducting polymers based technology has been evolving in several application fields, like opto-electronics, energy conversions and storage, sensors and actuators for mechanical and biological devices and others [1-6]. Detailed phenomenological comprehension of the dynamics of polarons and bipolarons, which are the charge carriers in these material, can improve the design and development of new applications.

Several studies has been carried out on the dynamics of scattering involving opposite charged quasi-particles [7-11], but we could not find any on quasi-particles with same sign charges. The present work addresses such situations in pristine chains of cispolyacetilene and polyparaphenylene, both simple and prototypical polymers whose analysis is relatively easy and can shed light on more complex systems.
\end{abstract}

To accomplish this, we follow a systematic numerical investigation using a SSH Hamiltonian model extended to include intra-site and nearest neighbors electronelectron interactions, developed over a two dimensional hexagonal lattice [12].

We identify an intermediary range of relative velocities for which the polaron passes through the bipolaron, both keeping their integrity as a elemental charge multiple $(e$, $2 e$ ) coupled to a distinct lattice deformation. Out of this: range, an elastic or quasi-elastic collision takes place, as expected, and from this we can estimate the ratio between effective masses of polaron and bipolaron.

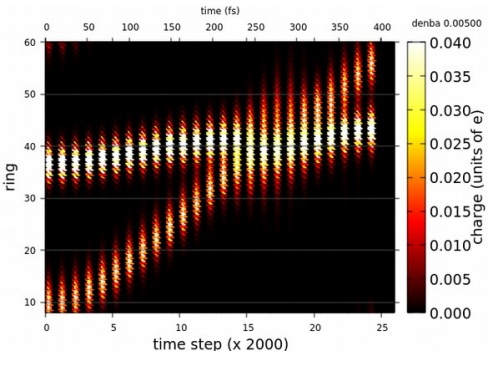

\section{References}

[1] Bundgaard E, Krebs FC (2007) Low band gap polymers for organic photovoltaics. Sol. Energ. Mat. Sol. Cells 91:954-985

[2] Zhu LM, Lei AW, Cao YL, Ai XP, Yang HX (2013) An all-organic rechargeable battery using bipolar polyparaphenylene as a redox-active cathode and anode. Chem. Commun. 49:567-569

[3] Borges, I Jr, Uhl E, Modesto-Costa L, Aquino AJA, Ĺischka H (2016) Insight into the Excited State Electronic and Structural Properties of the Organic Photovoltaic Donor Polymer Poly(thieno[3,4-b]thiophene benzodithiophene) by Means of ab Initio and Density Functional Theory. J. Phys. Chem. C 120(38):21818-21826 
[4] Burroughes JH, Bradley DDC, Brown AR. Marks RN, Mackay K, Friend RH, Burns PL, Holmes AB (1990) Light-emitting diodes based on conjugated polymers. Nature 347:539-541

[5] Sirringhaus H, Brown PJ, Friend RH, Nielsen MM, Bechgaard K, Langeveld-Voss BMW, Spiering AJH, Janssen RAJ, Meijer EW, Herwig P, de Leeuw DM (1999) Two-dimensional charge transport in self-organized, high-mobility conjugated polymers. Nature 401:685-688

[6] Guimard NK, Gomez N, Schmidt CE (2007) Conducting polymers in biomedical engineering. Prog. Polym. Sci. 32:876-921

[7] An, Z.; Di, B.; Wu, C. Q. (2008) Inelastic Scattering of Oppositely Charged Polarons in Conjugated Polymers. Eur. Phys. J. B. 63:71-77

[8] Sun, Z.; Stafström, S. (2011) Bipolaron Recombination in Conjugated Polymers. J. Chem. Phys. 135:074902-7

[9] Di, B.; Meng, Y.; Wang, Y. D.; Liu, X. J.; An, Z. (2011) Electroluminescence Enhancement in Polymer Light-Emitting Diodes Through Inelastic Scattering of Oppositely Charged Bipolarons. J. Chem. Phys. B. 115:9339-9344

[10] Ribeiro, L. A.; da Cunha, W. F.; Neto, P. H. O.; Gargano, R.; e Silva, G. M. (2013) Impurity Effects on Polaron-Exciton Formation in Conjugated Polymers. $J$. Chem. Phys. 139:174903-6

[11] da Cunha, W. F.; Junior, L. A. R.; Gargano, R.; e Silva, G. M. (2014) Critical Temperature and Products of Intrachain Polaron Recombination in Conjugated Polymers. Phys. Chem. Chem. Phys. 16:17072-17080

[12] Silva GM (2000) Electric-field effects on the competition between polarons and bipolarons in conjugated polymers. Phys. Rev. B 61:10777-10781 